\section{Research Square}

Preprints are preliminary reports that have not undergone peer review.

They should not be considered conclusive, used to inform clinical practice, or referenced by the media as validated information.

\title{
Regime Transition Shapes the Composition, Assembly Processes and Co-Occurrence Pattern of Bacterioplankton Community in a Large Eutrophic Freshwater Lake
}

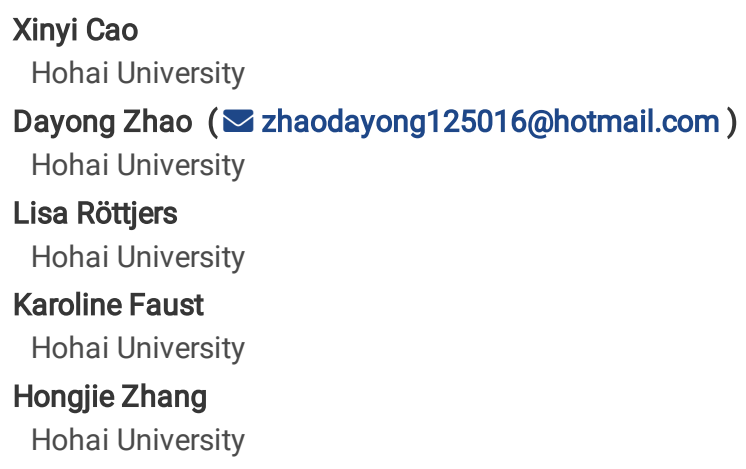

Research Article

Keywords: Freshwater lake, Regime shifts, Non-linear change, Bacterioplankton community, Network analysis

Posted Date: April 21st, 2021

DOI: https://doi.org/10.21203/rs.3.rs-427021/v1

License: (c) (i) This work is licensed under a Creative Commons Attribution 4.0 International License. Read Full License 


\section{Abstract}

At certain nutrient concentrations, shallow freshwater lakes are generally characterized by two contrasting ecological regimes with disparate patterns of biodiversity and biogeochemical cycles: a macrophyte-dominated regime (MDR) and a phytoplankton-dominated regime (PDR). To reveal ecological mechanisms that affect bacterioplankton along the regime shift, Illumina MiSeq sequencing of the 16S rRNA gene combined with a novel network clustering tool (Manta) were used to identify patterns of bacterioplankton community composition across the regime shift in Taihu Lake, China. Marked divergence in the composition and ecological assembly processes of bacterioplankton community were observed under the regime shift. The alpha diversity of bacterioplankton community was observed to consistently and continuously decrease with the regime shift from MDR to PDR, while the beta diversity presents the opposite. Moreover, as the regime shifted from MDR to PDR, the contribution of deterministic processes first decreased and then increased again closer to the PDR, most likely as a consequence of differences in nutrient concentration. The topological properties of bacterioplankton co-occurrence networks along the regime shift differed, and the co-occurrences among species changed in structure and were significantly shaped by the environmental variables along the regime transition from MDR to PDR. The divergent environmental state of the regimes with diverse nutritional status may be the most important factor that contributes to the dissimilarity of bacterioplankton community composition along the regime shift and could be represented by phosphorus concentrations as well as several indicator species.

\section{Introduction}

At certain eutrophic states, shallow lakes are generally characterized by two contrasting ecological regimes. These include a clear macrophytedominated regime (MDR) and a turbid phytoplankton-dominated regime (PDR) $[1,2]$. The shift between the two alternative states is related to nutrient concentrations, specifically phosphorus and nitrogen. These nutrients can have strong impacts on ecosystem structure and functioning and are generally introduced through human activities [3-5]. Once nutrient concentrations rise above a certain threshold, lakes may change from MDR to PDR and their ecosystems undergo drastic shifts. These changes include phytoplankton blooms, gradual or rapid disappearance of macrophytes and increased water turbidity [6-8]. These regimes may be alternative stable states, with presence of a specific regime determined by a lake's history. Laboratory studies have found evidence of such alternative stable state dynamics in smaller mesocosms [9,10]. However, evidence of alternative stable states in natural ecosystems is scarce due to the high complexity, as well as the temporal and spatial scale of such systems [11].

Taihu Lake presents a unique opportunity to investigate the impact of nutrients on these alternative regimes. Although it is challenging to infer whether these are truly alternative stable states in the temporal sense, the physiochemical characteristics and macrophyte distribution of its subregions reflect either the MDR, the PDR, or a transition between these two regimes [12]. This regime transition from MDR to PDR has been linked to changes in the lake nutritional state before as the nutrients alter the top-down effects on lower trophic levels [5,13,14]. The structure of the participating bacterial communities may be different due to the contrasting decomposition products of algae and macrophytes in MDR and PDR, respectively [15]. To date, there have been studies establishing major differences in bacterioplankton community composition and diversity between these two regimes or across seasons $[4,5,13,16]$. Our previous study found similar contrasting patterns, with bacterial communities in the MDR having fewer functional genes but more microbial associations compared to the PDR regime [3]. Here, we analyze the dynamics of bacterioplankton communities and link them to changes in physicochemical parameters. More specifically, we address the question whether bacterioplankton community composition changes linearly or non-linearly along the regime transition between MDR and PDR.

The underlying mechanisms that induce the variations in bacterial community composition between sites are often summarized in two ways: niche-based selection and neutral processes $[17,18]$. Nevertheless, there is a controversy about the relative importance of these two processes in driving microbial communities [19]. To resolve such issues, Stegen et al. (2013) developed a procedure for the quantitative estimation of the influence of processes such as drift, selection and dispersal on bacterial community structure. This procedure demonstrated that both stochastic and deterministic processes appear to govern the assembly processes of bacterial communities [20,21]. However, a more complete understanding of community composition in the context of eutrophic lakes requires a thorough description of the abiotic drivers of co-occurrence patterns [22]. An inter-regime bacterioplankton co-occurrence network can demonstrate how clusters of organisms are driven by abiotic factors along regime shifts in freshwater lakes $[23,24]$. Moreover, clusters in the species' co-occurrence networks may be indicative of ecological processes governing community structure, such as niche filtering and habitat preference [25]. Additionally, microbial co-occurrence networks can predict hub species and potential interactions between species [26], thereby contributing to a deeper understanding of the underlying mechanisms that dominate the assembly process of bacterioplankton communities along the regime shift of freshwater lakes.

Taihu Lake is a typical large shallow eutrophic lake composed of several connected lake zones that maintain distinct-different nutrition loadings [27]. High spatial heterogeneity in the abundance of macrophytes and phytoplankton suggests variation in the responses to eutrophication within the lake, which may be a result of a specific distribution pattern of critical nutrient loads in Taihu Lake [28]. In such a large shallow lake, where water is completely mixed, it is unlikely that dispersal limitation and fast adaptation to local conditions could occur. Studies on bacterioplankton communities across (spatial) regime shifts from MDR to PDR in Taihu Lake are of great significance to provide insights into the mechanism of biodiversity and regime maintenance in the lake ecosystem from the microbiological point of view. In this study, Illumina MiSeq sequencing of the 
16S rRNA genes was used to identify the patterns of bacterioplankton community composition across Taihu Lake, China. We addressed the following research questions (1) Whether the bacterioplankton community composition changes linearly or non-linearly with the regime transition from MDR to PDR? (2) Which process dominates the bacterioplankton community assembly along the regime transition? (3) Are there core factors or species that drive and maintain the changes in the bacterioplankton community composition along the regime transition?

\section{Methods}

\section{Sample collection and high-throughput sequencing}

The samples and sequencing data in this study came from our previous study [3]. Briefly, six sampling sites across Taihu Lake were selected along the transition from the macrophyte-dominated regime (MDR) to the phytoplankton-dominated regime (PDR) (MDR-Core1, MDR-Core2, MDR-Edge, PDR-Edge, PDR-Core2, PDR-Core1) (Fig. S1) in August 2013. Water sampling, large plankton removal and bacterioplankton collection were described in our previous study [3]. The physicochemical properties of the water samples, including the pH, dissolved oxygen (DO) and turbidity were measured in situ using a calibrated multifunction water quality sonde (YSI 6600, Yellow Springs, OH, USA). The concentrations of total nitrogen (TN), total phosphorus (TP), ammonium $\left(\mathrm{NH}_{4}{ }^{-}-\mathrm{N}\right)$, nitrate $\left(\mathrm{NO}_{3}^{-}-\mathrm{N}\right)$, nitrite $\left(\mathrm{NO}_{2}^{-}-\mathrm{N}\right)$, orthophosphate $\left(\mathrm{PO}_{4}{ }^{3-}-\mathrm{P}\right)$, dissolved total nitrogen (DTN) and dissolved total phosphorus (DTP), dissolved organic carbon (DOC) and concentrations of chlorophyll a (Chl a) were further determined [3].

The detailed information of DNA extraction, amplification, and high-throughput sequencing were described in our previous study [3]. In brief, microbial DNA was extracted, purified and the concentration and purity of the DNA was determined using the spectrophotometric method [29]. The bacterial 16S rRNA gene was PCR amplified and then sequenced using an Illumina MiSeq platform. The paired-end raw sequences were processed to control the quality by the Galaxy Pipeline (http://zhoulab5.rccc.ou.edu:8080/root/login?redirect=\%2F) and then processed with QIIME v1.9.1 [29] as described in our previous study [3]. The raw reads were deposited into the NCBI Sequence Read Archive (SRA) database (BioProject:

PRJNA511603).

\section{Statistical analyses}

The pipeline-based subsampled OTU table was used for the following statistical analyses. The OTU richness, Simpson evenness and Faith's phylogenetic diversity were calculated with the QIIME scripts 'alpha_diversity.py' [30,31]. Weighted UniFrac [32] was calculated to quantify the phylogenetic beta diversity of bacterioplankton communities [21]. A principal coordinates analysis (PCoA) plot was constructed using the BrayCurtis dissimilarity index and weighted UniFrac matrices with the 'vegan' package (version 2.5-6) [33] in R software (version 3.6.1). Akaike information criterion values for linear-regression model and quadratic-regression of correlations between bacterial phylum and total phosphorus were calculated to select the proper models (Table S1). The bacterioplankton community composition along the regime transition was compared using analysis of similarity (ANOSIM) with the 'vegan' package (version 2.5-6) [34]. The standardized transformation of all environmental variables was performed, prior to calculating Euclidean distances of environmental variables with the 'vegdist' command in the 'vegan' (version 2.5-6) package in R software (version 3.6.1) after standardized transformation. Mantel and partial Mantel tests were performed to determine if the differences in bacterioplankton community composition between the samples were correlated with environmental parameters using the 'vegan' package (version 2.5-6) in $\mathrm{R}$ [35].

\section{Network analysis}

The pipeline-based OTU table was further used for network analysis. The samples were divided into six groups along the transition from macrophyte-dominated regime (MDR) to the phytoplankton-dominated regime (MDR-Core1, MDR-Core2, MDR-Edge, PDR-Edge, PDR-Core2, PDRCore1) (Fig. S1). To avoid unreliable network inference on zero-rich taxa, only the most commonly abundant OTUs (those detected in at least 50\% of samples in each regime, that is, 5 samples in one sampling site) were considered. In order to avoid the taxon number biases, we further trimmed each community dataset of sampling sites into the same taxon number, finally keeping the 527 most-abundant OTUs. CoNet was used to individually construct networks for the six sampling sites following the protocols described previously $[41,42]$ with minor modifications. In brief, the distribution of all pair-wise scores was calculated for each of five similarity measures (Bray-Curtis dissimilarity, Kullback-Leibler dissimilarity, Pearson and Spearman correlation, and Mutual Information), and the top 1000 positive and 1000 negative edges supported by at least two measures were retained initially. For each measurement and edge, 100 permutations (with renormalization for correlation measures) and bootstrap scores were generated, following the ReBoot routine. The measure-specific $P$-value was then computed, merged using Brown's method and discarded applying Benjamini-Hochberg's false discovery rate correction (edges with $P \geq 0.05$ were removed) [42]. Edges with scores outside the $95 \%$ confidence interval defined by the bootstrap distribution or not supported by at least two measures were discarded as well [42]. Network topologies were calculated in R software using 'igraph' packages (version 1.2.4.1) [43], and networks were visualized using Cytoscape software (version 3.6.1) [44]. Environmental variables were further integrated into the networks to reveal the relationship between nodes and environmental variables. Only correlations between environmental variables and species that were significant $(P<0.05$, Benjamini-Hochberg adjust) and strong $(r$ 
$\geq 0.75$ or $r \leq-0.75$ ) were considered. A novel microbial association network clustering algorithm (Manta) (version 1.0.1), which determines the optimal cluster number automatically, was used to separate the networks into clusters with default settings [22] after calculating the global network based on all 54 samples across the regime shift from MDR to PDR. Indexes, including modularity, clustering coefficient, average path length, network diameter, average degree and graph density were calculated using the 'igraph' packages in R to describe the attributes of a network [45]. One thousand random networks were generated using the 'igraph' packages in R, and all of the indexes of the random networks were calculated individually. A statistical Z-test was used to verify if the network indexes between the observed and random networks were significantly different.

The topological roles of certain nodes were determined by within-cluster connectivity ( $\mathrm{Zi})$ and connectivity among clusters (Pi), which reflect the connection between a node to nodes within its cluster and those in other clusters [45,46]. Zi and Pi are calculated according to Guimerà and Amaral (2005). The nodes in a network are divided into four subcategories according to the simplified classification: peripheral nodes, connectors, cluster hubs and network hubs [46,47]. The topological properties of nodes in a co-occurrence network can reveal species that correlate in their responses to the environment and may therefore be indicators of these responses. The topological role of each OTU was determined according to the scatter plot of within-cluster connectivity $(\mathrm{Zi})$ and among-cluster connectivity ( $\mathrm{Pi})$ [48]; including: Peripheral nodes $(\mathrm{Zi} \leq 2.5, \mathrm{Pi} \leq 0.62)$ that have only a few links and seldom connect to other clusters; connectors $(\mathrm{Zi} \leq 2.5, \mathrm{Pi}>0.62)$ that are highly linked to several clusters; cluster hubs $(\mathrm{Zi}>2.5, \mathrm{Pi} \leq$ $0.62)$ that are highly connected to nodes in their own clusters; network hubs $(\mathrm{Zi}>2.5, \mathrm{Pi}>0.62)$ that act as both cluster hubs and connectors.

\section{Results}

\section{Environmental heterogeneity in the sampling sites across the regime transition}

The geographic distance was significantly correlated with Euclidean distance of environmental parameters (Fig. S2, $P<0.001)$, indicating that more distant samples were more dissimilar in terms of their environmental parameters. TP concentrations were significantly different along the regime transition from the macrophyte-dominated regime (MDR) to the phytoplankton-dominated regime (PDR) (Fig. S3). Furthermore, almost all of the environmental parameters at six sampling sites across the transition from MDR to PDR were significantly correlated with TP (Fig. S4). The concentrations of $\mathrm{TN}, \mathrm{NO}_{3}{ }^{-}-\mathrm{N}, \mathrm{TP}, \mathrm{DTP}, \mathrm{PO}_{4}{ }^{3-}-\mathrm{P}, \mathrm{DOC}$, and $\mathrm{Chl}$ a continuously increased with the regime shift from MDR to PDR, while the concentrations of DTN and $\mathrm{NO}_{2}{ }^{-}-\mathrm{N}$ significantly decreased with the regime shift (Fig. S4).

\section{Community composition and assembly processes of bacterioplankton altered along the regime shift from MDR to PDR}

In total, we obtained 1,877,021 high-quality sequences from the two regimes. The total OTU richness was 18,655 at a $97 \%$ similarity level for all samples. Indices of the OTU richness, phylogenetic diversity and Pielou's evenness of the bacterioplankton community significantly decreased along the regime shift from MDR to PDR (Fig. 1a). The NMDS plot revealed that based on both of the taxonomy and phylogeny, the bacterioplankton community clustered together for each site, along the regime transition from MDR to PDR (Fig. 1b). As the regime shifted from MDR to PDR, the beta diversity of bacterioplankton community increased and reached its peak at the PDR-Edge site (Fig. S5 and S6). The average relative abundance of bacterial phyla and genera changed along the regime shift from MDR to PDR (Fig. 2 and Fig. S7). Bacteroidetes, Betaproteobacteria and Actinobacteria dominated the bacterioplankton community at the MDR-Core1 site (Fig. 2a). As opposed to a gradual change of communities along the environmental gradient of regime transition from MDR to PDR, the results demonstrate that the relative abundance of all taxa changed with increased TP concentration linearly or non-linearly (Fig. $2 \mathrm{~b}, P<0.001$ in all cases). Moreover, the non-linear model fit better for most taxa (Table S1). Typically, as the regime shifted from MDR to PDR, the relative abundance of Betaproteobacteria decreased non-linearly and gradually, whereas abundance of Actinobacteria increased non-linearly and reached its peak at the MDR-Edge site. Firmicutes and Gammaproteobacteria became abundant at the PDR-Edge site, and respectively dominated the PDR-Core sites with a linear and non-linear tendency, respectively.

Both taxonomic and phylogenetic dissimilarity of bacterioplankton community were significantly correlated with environmental distance along the regime shift (Fig. S8, $P<0.05$ ). Concentrations of TP along the MDR and PDR showed significant negative correlations with the alpha diversity of the bacterioplankton community (Fig. 1a), indicating that the alpha diversity decreased with increasing nutrient concentration under the regime shift. Significant positive correlations between the TP dissimilarity and beta diversity of bacterioplankton community were also observed (Fig. 1c), indicating that the differences of TP concentration between the samples contribute to the heterogeneity of bacterioplankton communities along the regime shift from MDR to PDR. Based on the Mantel test and partial Mantel test results (Table S2), the bacterioplankton community was significantly correlated with most of the environmental parameters along the regime shift $(P<0.05)$, especially for TP $(\mathrm{R}=0.7645$ and 0.5377 for Mantel test and partial Mantel test, respectively). The PCoA plot further highlighted that the community composition aligned well to environmental parameters (Fig. 3). 
Almost all of the betaNTI values were considerably less than -2 (Fig. S9a). This suggests that deterministic processes dominate in shaping the bacterioplankton communities along the two regimes [40]. Moreover, as the regime shifted from MDR to PDR, the contribution of deterministic processes first decreased in the edge sites and then increased again closer to the PDR. Furthermore, the assembly analysis revealed the quantitative importance of variable selection (selection under heterogeneous abiotic and biotic environmental conditions leading to more dissimilar structures among communities; also called variable selection), homogeneous selection (selection under homogeneous abiotic and biotic environmental conditions leading to more similar structures among communities), dispersal limitation, homogeneous dispersal, and other processes in shaping the community patterns of the bacterioplankton community along the two regimes (Fig. S9b). At a relative importance of more than $60 \%$, variable selection contributed the most to the assembly processes of bacterioplankton communities in these six sites. At $28.58 \%$, homogenizing dispersal was the second-most important assembly process of the bacterioplankton community.

\section{Co-occurrence patterns of the bacterioplankton community along the regime shift}

We constructed six co-occurrence networks from the six sampling sites spaced out along the regime transition. These sampling sites, located along the regime transition from MDR to PDR, were labelled MDR-Core1, MDR-Core2, MDR-Edge, PDR-Edge, PDR-Core2 and PDR-Core1. The derived cooccurrence networks featured environment-specific species co-occurrence relationships (Fig. 4 and Fig. S10). Subnetworks inferred from datasets trimmed into uniform number of OTUs contained distinct co-occurrence patterns in terms of species composition (Fig. 4). Moreover, these regimespecific co-occurrence relationships displayed network characteristics that were significantly different compared to random networks (Table 1). The Z-test results comparing a variety of indexes of the observed correlation-based network with those of random networks, including Modularity, Transitivity and Network diameter, indicated that the networks among species along the regime shift from PDR and MDR were all nonrandom $(P<$ 0.001 in all cases, Table 1). Based on the size and taxonomic information, the bacterioplankton community network changed along the regime transition from MDR to PDR (Table 1 and Fig. S10). Bacteroidetes, Betaproteobacteria and Actinobacteria dominated and clustered in the MDR sites, whereas Firmicutes and Gammaproteobacteria dominated and clustered in the PDR sites.

\section{Discussion}

\section{Phosphorus concentrations as an indicator of regime transition}

This and previous studies showed that the lake water displays significant environmental differences along the regime transition from the macrophyte-dominated regime (MDR) to the phytoplankton-dominated regime (PDR) $[12,49,50]$. Certain environmental parameters have been suggested to be responsible for the observed differences in bacterioplankton community, such as pH [51] and nutrient enrichment [5], as well as the occurrence of phytoplankton [3,52], which are frequently associated with eutrophication. The mechanisms of the regime shift can involve multiple drivers as well as interactions of macrophytes, phytoplankton, nutrients, and herbivorous waterfowl [53]. Here, we focused on the phosphorus concentration because it is commonly targeted to mitigate eutrophication and it is proposed in previous studies that regime shifts from MDR to PDR in shallow lakes are mostly induced by increasing nutrient concentrations, especially phosphorus [2,52,53]. In this study we found that almost all of the environmental parameters at six sampling sites across the transition from MDR to PDR were significantly linearly correlated with TP, especially turbidity (Fig. S4). Turbidity is a measure of water transparency, which is mainly influenced by concentrations of phytoplankton and resuspended sediment particles [13,14]. The wind-driven process of sediment re-suspension is much stronger in PDR-Core sites than in MDR-Core sites in Taihu Lake because the submersed macrophyte communities in MDR have a calming effect on the water column and sediment turbulence $[8,54]$, which is consistent with the results found in this study.

\section{Compositional dissimilarity of bacterioplankton communities differed along regime transition}

Our results indicate that the bacterioplankton community was significantly correlated with environmental factors at the regime transition, especially TP, which is regarded as a limiting nutrient in the eutrophic freshwater lakes that contribute to regime shift [55-57]. A significant difference between bacterioplankton community in lake ecosystems with disparate environmental variables has also been widely observed $[13,58,59]$. The alpha diversity of bacterioplankton communities along the regime transition from MDR to PDR was observed to decrease and linearly correlate with TP significantly, which is consistent with the observation that bacterial diversity was negatively affected by phytoplankton blooms [60]. In general, when the evenness of bacterioplankton community decreases with the regime shift, the diversity does so too, indicating that a particular species becomes more dominant with the regime transition [61]. Also, several taxonomic groups displayed substantial changes in abundance as the regime shifted (Fig. 2 and Fig. S7). Regime shifts provide a mechanism for selection, as abundant OTUs become rare or even more abundant due to their sensitivity to changes in the environmental conditions [1,3]. Intriguingly, these changes were occasionally non-linear, suggesting that taxa had different optima along the MDR-PDR gradient. For a number of taxa, e.g., Acidobacteria and Cyanobacteria, the relationship to TP is well described by quadratic functions, which means that the taxon has an optimal value for TP and declines in abundance below and above that value, as opposed to a gradual change of bacterioplankton communities along the environmental gradient along the regime 
shift from MDR to PDR. It has been demonstrated that Betaproteobacteria tends to be the dominant group in relatively oligotrophic lakes [12,13], while Firmicutes, which appears to be involved in DOC degradation [62,63], often become dominant in eutrophic lakes alongside blooms of Cyanobacteria [64]. Our results, that Betaproteobacteria and Firmicutes were negative and positive linearly correlated with TP, are consistent with these findings. Therefore, those consistently variable OTUs might be used as discriminant taxa for the different regimes.

\section{Changes in assembly processes of bacterioplankton communities were attributed to regime transition}

Although the deterministic processes were observed to dominate in shaping the bacterioplankton communities in both the MDR-Core and PDR-Core sites, the deterministic process in MDR-Core sites were observed to be stronger than in PDR-Core sites. According to other experimental studies, competition among species could be reduced in more productive environments, hence weakening selection and strengthening the stochasticity of bacterial communities [5,65]. Previous work has also shown that the degree of determinism increases in extreme or low resource environments for the assembly process of microbial community [66-69]. The stronger deterministic process in MDR-Core sites may be due to lower nutrient concentrations compared to PDR-Core-sites, leading to relatively stronger selection due to increased competition for resources and less diverse resources [49]. As to the decreased contribution of deterministic processes in the edge sites of MDR and PDR, there could be two reasons. On the one hand, edge sites could provide a more favorable living environment because of the higher nutrient concentrations compared to MDR-Core sites and lower algal toxin pressure compared to PDR-Core sites [64]. On the other hand, water disturbance driven by strong wind in the edge sites of the two regimes in Lake Taihu could also have resulted in an increase of the disturbance of environmental conditions and the passive dispersal of species, hence increasing the stochasticity of bacterioplankton community $[65,70]$. While the comparably strong deterministic process in PDR-Core sites may be due to the algal toxin pressure that comes from Cyanobacteria bloom [62], but weakened by the extremely abundant resources [65]. Of the investigated ecological processes, variable selection contributed the most to the assembly of bacterioplankton community (Fig. S9b). In freshwater lakes, both community structure and the assembly processes of bacterioplankton have been shown to be intensively influenced by nutrient loading $[5,49]$ as well as submerged macrophytes $[8,12]$. The heterogeneous pattern of the bacterioplankton community assembly processes in this study could therefore be attributed to differences in nutrient loading along the regime shift from MDR to PDR (Fig. 5).

\section{Regime transition revealed by network clusters and hub species}

In ecological systems, coexistence is potentially supported by niche processes like environmental filtering, as the different filters lead to establishment of different communities $[17,40]$. Species that share similar ecological niches may compete or cooperate to resist environmental pressure when resources are scarce or under environmental stress [71,72]. Compared to the MDR-core sites, the Cyanobacteria bloom caused by high concentration of TP in PDR-Core sites strengthen selection due to its algal toxin [60,62]. The modularity of the site-specific co-occurrence network varied along the regime shift (Table 1). Previous studies have shown the existence of environmentally driven modules [73,74]. In this study we also found that closely related taxa tended to be positively interconnected and clustered together (Fig. 4). Moreover, we found several hub species in the three network clusters, which are likely indicators of the effect of the regime shift on the bacterioplankton community. The first and third cluster contain taxa that dominate the MDR or PDR regime, respectively. These are also the taxa that consistently increase or decrease across the environmental gradient (Fig. 2). For instance, Firmicutes dominating cluster 3 and the PDR regime increase with TP while Betaproteobacteria dominating cluster 1 and the MDR regime decrease with TP. The taxa in the second cluster show more subtle patterns. Actinobacteria first increase and then decrease with TP, thus differing in their response from the Firmicutes, whereas Gammaproteobacteria increase with TP but then saturate, in contrast to both the Firmicutes and the Actinobacteria. Thus, cluster 2 groups taxa which benefit from increased TP, but only up to a point. Given that clusters in microbial co-occurrence networks may represent different niches [23], the TP-correlated clusters indicate high similarity in species' co-occurrence patterns along the regime shift and may be summarized by the hub species in these clusters (Fig. 5).

\section{Conclusions}

All results suggest that the ecological regimes drive a marked divergence in the community structure of bacterioplankton communities (Fig. 5). The alpha diversity and evenness index linearly decreased with the regime shift, indicating that particular species become more dominant with the regime transition. The hub species that could reflect the regime conditions belonged to the phyla Betaproteobacteria, and Actinobacteria in MDRCore sites, phyla Betaproteobacteria, Gammaproteobacteria and Actinobacteria in edge sites, phyla Cyanobacteria in PDR-Core sites (Fig. 5). We demonstrated that the contribution of deterministic process decreased at the edge sites when the regime shifted from MDR to PDR, most likely as a consequence of differences in nutrient concentration (especially TP) and the presence of macrophytes. The bacterioplankton co-occurrence networks were clearly linked to environmental variables and were divided into three clusters that reflected the regime shift. The diverse nutrient status may be the most important factor that contributes to the dissimilarity of bacterioplankton community composition along the regime shift. Our results provide a better understanding of the interplay between nutrients and taxonomic composition in macrophyte- and phytoplanktondominated freshwater regimes. 


\section{Declarations \\ Funding}

This work was supported by the National Natural Science Foundation of China (41871096); the Natural Science Foundation of Jiangsu Province, China (BK20181311); the Fundamental Research Funds for the Central Universities (2018B43414; B200203051); and the China Scholarship

Council (No. 201906710009).

\section{Conflicts of interest}

The authors declare that they have no known competing financial interests or personal relationships that could have appeared to influence the work reported in this paper.

\section{Availability of data and material}

The raw reads were deposited into the NCBI Sequence Read Archive (SRA) database (BioProject: PRJNA511603).

\section{Code availability}

Not applicable.

\section{Authors' contributions}

Conceptualization: Dayong Zhao, Xinyi Cao; Methodology: Lisa Röttjers, Karoline Faust, Xinyi Cao; Formal analysis and investigation: Xinyi Cao, Lisa Röttjers, Karoline Faust; Writing - original draft preparation: Xinyi Cao, Hongjie Zhang; Writing - review and editing: Xinyi Cao, Lisa Röttjers, Karoline Faust, Dayong Zhao, Hongjie Zhang; Funding acquisition: Dayong Zhao; Supervision: Dayong Zhao.

\section{Ethical approval}

This article does not contain any studies with human participants or animals performed by any of the authors.

\section{Consent to participate}

Not applicable.

\section{Consent for publication}

The publisher has the authors' permission to publish the content presented herein.

Acknowledgements

We are especially grateful to Qinglong Wu for his experiment design of this study, Yujing Wang for her assistance in the sample collection and the measurement of physicochemical parameters. This work was supported by the National Natural Science Foundation of China (41871096); the Natural Science Foundation of Jiangsu Province, China (BK20181311); the Fundamental Research Funds for the Central Universities (2018B43414; B200203051); and the China Scholarship Council (No. 201906710009).

\section{References}

1. Scheffer, M \& van Nes, EH (2007) Shallow lakes theory revisited: various alternative regimes driven by climate, nutrients, depth and lake size. Hydrobiologia 584: 455-466. https://doi.org/10.1007/s10750-007-0616-7

2. Scheffer, M, Hosper, SH, Meijer, ML, Moss, B \& Jeppesen, E (1993) Alternative Equilibria in Shallow Lakes. Trends in Ecology \& Evolution 8: 275279. https://doi.org/10.1016/0169-5347(93)90254-M

3. Wang, Y, Cao, X et al. (2020) Distinct shifts in bacterioplankton community composition and functional gene structure between macrophyteand phytoplankton-dominated regimes in a large shallow lake. Limnology and Oceanography 65: S208-S219. 
https://doi.org/10.1002/Ino.11373

4. Van der Gucht, K, Sabbe, K et al. (2010) Contrasting bacterioplankton community composition and seasonal dynamics in two neighbouring hypertrophic freshwater lakes. Environmental Microbiology 3: 680-690. https://doi.org/10.1046/j.1462-2920.2001.00242.x

5. Haukka, K, Kolmonen, E et al. (2006) Effect of nutrient loading on bacterioplankton community composition in lake mesocosms. Microbial Ecology 51: 137-146. https://doi.org/10.1007/s00248-005-0049-7

6. Hanashiro, FTT, Mukherjee, S et al. (2019) Freshwater Bacterioplankton Metacommunity Structure Along Urbanization Gradients in Belgium. Frontiers in Microbiology 10: 743. https://doi.org/10.3389/fmicb.2019.00743

7. González Sagrario, MA, Jeppesen, E et al. (2005) Does high nitrogen loading prevent clear-water conditions in shallow lakes at moderately high phosphorus concentrations? Freshwater Biology 50: 27-41. https://doi.org/10.1111/j.1365-2427.2004.01290.x

8. Wetzel RG., Søndergaard M. (1998) Role of Submerged Macrophytes for the Microbial Community and Dynamics of Dissolved Organic Carbon in Aquatic Ecosystems. In: Jeppesen E., Søndergaard M., Søndergaard M., Christoffersen K. (eds) The Structuring Role of Submerged Macrophytes in Lakes. Springer, New York, pp 133-148

9. Khazaei, T, Williams, RL et al. (2020) Metabolic multistability and hysteresis in a model aerobe-anaerobe microbiome community. Science Advances 6: eaba0353. https://doi.org/10.1126/sciadv.aba0353

10. Hillebrand, H, Langenheder, S et al. (2018) Decomposing multiple dimensions of stability in global change experiments. Ecology Letters 21: 2130. https://doi.org/10.1111/ele.12867

11. Gonze, D, Lahti, L, Raes, J \& Faust, K (2017) Multi-stability and the origin of microbial community types. The ISME journal 11: $2159-2166$. https://doi.org/10.1038/ismej.2017.60

12. Wu, QL, Zwart, G et al. (2010) Submersed macrophytes play a key role in structuring bacterioplankton community composition in the large, shallow, subtropical Taihu Lake, China. Environmental Microbiology 9: 2765-2774. https://doi.org/10.1111/j.1462-2920.2007.01388.x

13. Wu, QL (2013) Impacts of regime shift between phytoplankton and macrophyte on the microbial community structure and its carbon cycling in lakes. Microbiology China 40: 87-97. https://doi.org/10.13344/j.microbiol.china.2013.01.003

14. Jeppesen, E, Jensen, JP et al. (1997) Top-down control in freshwater lakes: The role of nutrient state, submerged macrophytes and water depth. Hydrobiologia 342: 151-164. https://doi.org/10.1023/a:1017046130329

15. Han, X, Schubert, CJ, Fiskal, A, Dubois, N \& Lever, MA (2020) Eutrophication as a driver of microbial community structure in lake sediments. Environmental Microbiology 22: 3446-3462. https://doi.org/10.1111/1462-2920.15115

16. Wang, Y, Li, H, Xing, P \& Wu, Q (2017) Contrasting patterns of free-living bacterioplankton diversity in macrophyte-dominated versus phytoplankton blooming regimes in Dianchi Lake, a shallow lake in China. Chinese Journal of Oceanology \& Limnology 35: 336-349. https://doi.org/10.1007/s00343-016-5277-9

17. Langenheder, S \& Székely, AJ (2011) Species sorting and neutral processes are both important during the initial assembly of bacterial communities. The ISME journal 5: 1086-1094. https://doi.org/10.1038/ismej.2010.207

18. Stegen, JC, Lin, X, Fredrickson, JK \& Konopka, AE (2015) Estimating and mapping ecological processes influencing microbial community assembly. Frontiers in Microbiology 6: 370. https://doi.org/10.3389/fmicb.2015.00370

19. Zhou, J \& Ning, D (2017) Stochastic community assembly: does it matter in microbial ecology? Microbiology and Molecular Biology Reviews 81. https://doi.org/10.1128/mmbr.00002-17

20. Stegen, JC, Lin, X et al. (2013) Quantifying community assembly processes and identifying features that impose them. The ISME journal 7: 2069-2079. https://doi.org/10.1038/ismej.2013.93

21. Wang, J, Shen, J et al. (2013) Phylogenetic beta diversity in bacterial assemblages across ecosystems: deterministic versus stochastic processes. The ISME journal 7: 1310-1321. https://doi.org/10.1038/ismej.2013.30

22. Röttjers, L \& Faust, K (2020) manta: a Clustering Algorithm for Weighted Ecological Networks. Msystems 5. https://doi.org/10.1128/mSystems.00903-19

23. Röttjers, L \& Faust, K (2018) From hairballs to hypotheses-biological insights from microbial networks. FEMS Microbiology Reviews 42: 761780. https://doi.org/10.1093/femsre/fuy030

24. Ma, B, Wang, Y et al. (2020) Earth microbial co-occurrence network reveals interconnection pattern across microbiomes. Microbiome 8: 1-12. https://doi.org/10.1186/s40168-020-00857-2

25. Lima-Mendez, G, Faust, K et al. (2015) Determinants of community structure in the global plankton interactome. Science 348 : 1262073. https://doi.org/10.1126/science.1262073

26. Berry, D \& Widder, S (2014) Deciphering microbial interactions and detecting keystone species with co-occurrence networks. Frontiers in Microbiology 5: 219. https://doi.org/10.3389/fmicb.2014.00219

27. Qin, B, Liu, Z \& Havens, K (2007) Eutrophication of Shallow Lakes with Special Reference to Lake Taihu, China. Springer, Netherlands

28. Janssen, AB, de Jager, VC et al. (2017) Spatial identification of critical nutrient loads of large shallow lakes: implications for Lake Taihu (China). Water Research 119: 276-287. https://doi.org/10.1016/j.watres.2017.04.045

Page 8/16 
29. Caporaso, JG, Lauber, CL et al. (2012) Ultra-high-throughput microbial community analysis on the Illumina HiSeq and MiSeq platforms. Isme Journal Multidisciplinary Journal of Microbial Ecology 6: 1621-1624. https://doi.org/10.1038/ismej.2012.8

30. Edgar, RC (2013) UPARSE: highly accurate OTU sequences from microbial amplicon reads. Nature Methods 10: $996-998$. https://doi.org/10.1038/nmeth.2604

31. Faith, DP (1992) Conservation evaluation and phylogenetic diversity. Biological Conservation 61: 1-10. https://doi.org/10.1016/00063207(92)91201-3

32. Lozupone, C \& Knight, R (2005) UniFrac: a New Phylogenetic Method for Comparing Microbial Communities. Applied and Environmental Microbiology 71: 8228-8235. https://doi.org/10.1128/AEM.71.12.8228-8235.2005

33. Oksanen, J, Blanchet, FG et al. (2013) vegan: Community Ecology Package. R package version 2: http://CRAN.R-project.org/package=vegan

34. Zapala, MA \& Schork, NJ (2006) Multivariate regression analysis of distance matrices for testing associations between gene expression patterns and related variables. Proceedings of the National Academy of Sciences 103: 19430-19435.

https://doi.org/10.1073/pnas.0609333103

35. Legendre, P \& Legendre, LF (2012) Numerical ecology. 3rd English edn, Vol. 24 Elsevier Science

36. Price, MN, Dehal, PS \& Arkin, AP (2010) FastTree 2-approximately maximum-likelihood trees for large alignments. PLoS One 5: e9490. https://doi.org/10.1371/journal.pone.0009490

37. Dini-Andreote, F, Stegen, JC, Van Elsas, JD \& Salles, JF (2015) Disentangling mechanisms that mediate the balance between stochastic and deterministic processes in microbial succession. Proceedings of the National Academy of Sciences 112: E1326-E1332. https://doi.org/10.1073/pnas.1414261112

38. Webb, CO, Ackerly, DD, McPeek, MA \& Donoghue, MJ (2002) Phylogenies and community ecology. Annual Review of Ecology and Systematics 33: 475-505. https://doi.org/10.1146/annurev.ecolsys.33.010802.150448

39. Kembel, SW, Cowan, PD et al. (2010) Picante: R tools for integrating phylogenies and ecology. Bioinformatics 26: $1463-1464$. https://doi.org/10.1093/bioinformatics/btq166

40. Stegen, JC, Lin, X, Konopka, AE \& Fredrickson, JK (2012) Stochastic and deterministic assembly processes in subsurface microbial communities. The ISME journal 6: 1653-1664. https://doi.org/10.1038/ismej.2012.22

41. Weiss, S, Treuren, WV et al. (2016) Correlation detection strategies in microbial data sets vary widely in sensitivity and precision. The ISME journal 10: 1669-1681. https://doi.org/10.1038/ismej.2015.235

42. Faust, K \& Raes, J (2012) Microbial interactions: from networks to models. Nature Reviews Microbiology 10: $538-550$. https://doi.org/10.1038/nrmicro2832

43. Ognyanova, K (2016) Network Analysis and Visualization with R and igraph. https://www.kateto.net/networks-r-igraph

44. Shannon, P, Markiel, A et al. (2003) Cytoscape: A Software Environment for Integrated Models of Biomolecular Interaction Networks. Genome Research 13: 2498-2504. https://doi.org/10.1101/gr.1239303

45. Csardi, G (2006) The igraph software package for complex network research. Vol. 1695

46. Guimerà, R \& Amaral, LAN (2005) Functional cartography of complex metabolic networks. Nature 433: 895-900. https://doi.org/10.1038/nature03288

47. Guimerà, R, Sales-Pardo, M \& Amaral, LAN (2007) Classes of complex networks defined by role-to-role connectivity profiles. Nature Physics 3: 63-69. https://doi.org/10.1038/nphys489

48. Deng, Y, Jiang, YH et al. (2012) Molecular ecological network analyses. BMC Bioinformatics 13. https://doi.org/10.1186/1471-2105-13-113

49. Zhao, D, Cao, X et al. (2017) The heterogeneity of composition and assembly processes of the microbial community between different nutrient loading lake zones in Taihu Lake. Applied Microbiology and Biotechnology 101: 1-11. https://doi.org/10.1007/s00253-017-8327-0

50. Zhou, L, Wu, QL, Zhang, B, Zhao, Y \& Zhao, B (2016) Occurrence, spatiotemporal distribution, mass balance and ecological risks of antibiotics in subtropical shallow Lake Taihu, China. Environmental Science: Processes \& Impacts 18: 500-513. https://doi.org/10.1039/c6em00062b

51. Ren, L, Song, $X$ et al. (2017) Contrasting patterns of freshwater microbial metabolic potentials and functional gene interactions between an acidic mining lake and a weakly alkaline lake. Limnology \& Oceanography 63: S354-S366. https://doi.org/10.1002/Ino.10744

52. Brothers, SM, Hilt, S et al. (2013) A regime shift from macrophyte to phytoplankton dominance enhances carbon burial in a shallow, eutrophic lake. Ecosphere 4: 1-17. https://doi.org/10.1890/ES13-00247.1

53. Carpenter, SR \& Lathrop, RC (2008) Probabilistic estimate of a threshold for eutrophication. Ecosystems 11: $601-613$. https://doi.org/10.1007/S10021-008-9145-0

54. Qin, B, Chen, W \& Hu, W. (2004) Succession of ecological environment and its mechanism in Lake Taihu (in Chinese). China Science Press, Beijing

55. Molinos-Senante, M, Hernández-Sancho, F, Sala-Garrido, R \& Garrido-Baserba, M (2011) Economic feasibility study for phosphorus recovery processes. Ambio 40: 408-416. https://doi.org/10.1007/s13280-010-0101-9

Page $9 / 16$ 
56. Huang, L, Fang, H, He, G, Jiang, H \& Wang, C (2016) Effects of internal loading on phosphorus distribution in the Taihu Lake driven by wind waves and lake currents. Environmental Pollution 219: 760-773. https://doi.org/10.1016/j.envpol.2016.07.049

57. Elser, JJ, Marzolf, ER \& Goldman, CR (1990) Phosphorus and Nitrogen Limitation of Phytoplankton Growth in the Freshwaters of North America: A Review and Critique of Experimental Enrichments. Canadian Journal of Fisheries \& Aquatic Sciences 47: $1468-1477$. https://doi.org/10.1139/f90-165

58. Wu, L, Ge, G, Gong, S, Li, S \& Wan, J (2012) Diversity and composition of the bacterial community of Poyang Lake (China) as determined by 16S rRNA gene sequence analysis. World Journal of Microbiology \& Biotechnology 28: 233-244. https://doi.org/10.1007/s11274-011-0812-5

59. Zeng, J, Bian, YQ, Xing, P \& Wu, QL (2012) Macrophyte Species Drive the Variation of Bacterioplankton Community Composition in a Shallow Freshwater Lake. Applied and Environmental Microbiology 78: 177-184. https://doi.org/10.1128/AEM.05117-11

60. Wemheuer, B, Güllert, S et al. (2014) Impact of a phytoplankton bloom on the diversity of the active bacterial community in the southern North Sea as revealed by metatranscriptomic approaches. FEMS Microbiology Ecology 87: 378-389. https://doi.org/10.1111/1574-6941.12230

61. Kim, B-R, Shin, J et al. (2017) Deciphering diversity indices for a better understanding of microbial communities. Journal of Microbiology and Biotechnology 27: 2089-2093. https://doi.org/10.4014/jmb.1709.09027

62. Sison-Mangus, MP, Jiang, S, Kudela, RM \& Mehic, S (2016) Phytoplankton-associated bacterial community composition and succession during toxic diatom bloom and non-bloom events. Frontiers in microbiology 7: 1433. https://doi.org/10.3389/fmicb.2016.01433

63. Xing, P, Guo, L, Tian, W \& Wu, QL (2010) Novel Clostridium populations involved in the anaerobic degradation of Microcystis blooms. The ISME journal 5: 792-800. https://doi.org/10.1038/ismej.2010.176

64. Li, J, Wang, G et al. (2017) Dynamic changes of bacterial community structure in the occurrence process of cyanobacterial bloom. Journal of China Agricultural University 22: 134-142. https://doi.org/10.11841/j.issn.1007-4333.2017.07.16

65. Zhou, J, Deng, Y et al. (2014) Stochasticity, succession, and environmental perturbations in a fluidic ecosystem. Proceedings of the National Academy of Science 111: 836-845. https://doi.org/10.1073/pnas.1324044111

66. Zhou, J, Liu, W et al. (2013) Stochastic Assembly Leads to Alternative Communities with Distinct Functions in a Bioreactor Microbial Community. Mbio 4: 49-52. https://doi.org/10.1128/mBio.00584-12

67. Van der Plas, F, Anderson, TM \& Olff, H (2012) Trait similarity patterns within grass and grasshopper communities: multitrophic community assembly at work. Ecology 93: 836-846. https://doi.org/10.1890/11-0975.1

68. Gerisch, M \& Dziock, F (2012) More species, but all do the same: contrasting effects of flood disturbance on ground beetle functional and species diversity. Oikos 121: 508-515. https://doi.org/10.1111/j.1600-0706.2011.19749.x

69. Chase, JM (2010) Stochastic community assembly causes higher biodiversity in more productive environments. Science 328: $1388-1391$. https://doi.org/10.1126/science. 1187820

70. Hu, A, Ju, F et al. (2017) Strong impact of anthropogenic contamination on the co-occurrence patterns of a riverine microbial community. Environmental Microbiology 19: 4993-5009. https://doi.org/10.1111/1462-2920.13942

71. Chaffron, S, Rehrauer, H, Pernthaler, J \& Mering, CV (2010) A global network of coexisting microbes from environmental and whole-genome sequence data. Genome Research 20: 947-959. https://doi.org/10.1007/s002890050103

72. Tilman D (2007) Interespecific competition and multispecies coexistence. In: May RM, McLean A (eds) Theoretical ecology principles and applications. University Press, Oxford, pp 84-97

73. Cao, X, Zhao, D et al. (2018) Heterogeneity of interactions of microbial communities in regions of Taihu Lake with different nutrient loadings: A network analysis. Scientific Reports 8: 1-11. https://doi.org/10.1038/s41598-018-27172-z

74. Newman, MEJ (2006) Modularity and community structure in networks. Proceedings of the National Academy of Sciences 103: $8577-8582$. https://doi.org/10.1073/pnas.0601602103

\section{Tables}

Table 1 Topological properties of the empirical network and associated random network for bacterioplankton community along the regime transition from macrophyte-dominated regime (MDR) to phytoplankton-dominated regime (PDR) in Lake Taihu. 


\begin{tabular}{|c|c|c|c|c|c|c|c|c|c|c|c|}
\hline \multirow[b]{2}{*}{ Sites } & \multicolumn{8}{|c|}{ Empirical network } & \multicolumn{3}{|c|}{ Random network ${ }^{b}$} \\
\hline & Nodes & Edges & & & Modularity & Transitivity & $\begin{array}{l}\text { Network } \\
\text { diameter }\end{array}$ & $\begin{array}{l}\text { Average } \\
\text { degree }\end{array}$ & $\begin{array}{l}\text { Modularity } \\
\text { (SD) }\end{array}$ & $\begin{array}{l}\text { Transitivity } \\
\text { (SD) }\end{array}$ & $\begin{array}{l}\text { Network } \\
\text { diameter } \\
\text { (SD) }\end{array}$ \\
\hline \multirow{8}{*}{$\begin{array}{l}\text { Global } \\
\text { network }\end{array}$} & \multirow[t]{8}{*}{614} & \multirow[t]{2}{*}{ Overall } & positive & 2150 & \multirow[t]{8}{*}{$0.464^{\mathrm{a}}$} & \multirow[t]{8}{*}{$0.269^{a}$} & \multirow[t]{8}{*}{$9^{a}$} & \multirow[t]{8}{*}{12.65} & \multirow{8}{*}{$\begin{array}{l}0.243 \\
(0.004)\end{array}$} & \multirow{8}{*}{$\begin{array}{l}0.021 \\
(0.001)\end{array}$} & \multirow{8}{*}{$\begin{array}{l}4.427 \\
(0.495)\end{array}$} \\
\hline & & & negative & 1734 & & & & & & & \\
\hline & & \multirow[t]{2}{*}{ Cluster1 } & positive & 697 & & & & & & & \\
\hline & & & negative & 7 & & & & & & & \\
\hline & & \multirow[t]{2}{*}{ Cluster2 } & positive & 691 & & & & & & & \\
\hline & & & negative & 15 & & & & & & & \\
\hline & & \multirow[t]{2}{*}{ Cluster3 } & positive & 422 & & & & & & & \\
\hline & & & negative & 0 & & & & & & & \\
\hline \multirow{2}{*}{$\begin{array}{l}\text { MDR- } \\
\text { Core1 }\end{array}$} & \multirow[t]{2}{*}{301} & positive & & 353 & \multirow[t]{2}{*}{$0.791^{b}$} & \multirow[t]{2}{*}{$0.360^{\mathrm{a}}$} & \multirow[t]{2}{*}{$13^{a}$} & \multirow[t]{2}{*}{3.535} & 0.542 & 0.011 & 9.933 \\
\hline & & negative & & 179 & & & & & $(0.008)$ & $(0.004)$ & $(0.807)$ \\
\hline \multirow{2}{*}{$\begin{array}{l}\text { MDR- } \\
\text { Core2 }\end{array}$} & \multirow[t]{2}{*}{517} & positive & & 241 & \multirow[t]{2}{*}{$0.454^{b}$} & \multirow[t]{2}{*}{$0.291^{a}$} & \multirow[t]{2}{*}{$19^{a}$} & \multirow[t]{2}{*}{1.624} & 0.850 & 0.003 & 25.63 \\
\hline & & negative & & 179 & & & & & $(0.013)$ & $(0.003)$ & $(3.385)$ \\
\hline \multirow{2}{*}{$\begin{array}{l}\text { MDR- } \\
\text { Edge }\end{array}$} & \multirow[t]{2}{*}{429} & positive & & 286 & \multirow[t]{2}{*}{$0.671^{b}$} & \multirow[t]{2}{*}{$0.301^{a}$} & $21^{a}$ & 2.275 & 0.721 & 0.005 & 16.472 \\
\hline & & negative & & 202 & & & & & $(0.010)$ & $(0.003)$ & $(1.617)$ \\
\hline PDR- & 431 & positive & & 1439 & $0.878^{b}$ & $0.453^{a}$ & $21^{a}$ & 7.360 & 0.337 & 0.017 & 6.003 \\
\hline & & negative & & 147 & & & & & $(0.005)$ & $(0.002)$ & $(0.308)$ \\
\hline PDR- & 381 & positive & & 1143 & $0.964^{\mathrm{b}}$ & $0.411^{a}$ & $11^{\mathrm{a}}$ & 8.661 & 0.303 & 0.023 & 5.134 \\
\hline & & negative & & 507 & & & & & $(0.005)$ & $(0.002)$ & $(0.341)$ \\
\hline PDR- & 269 & positive & & 419 & $0.691^{b}$ & $0.425^{a}$ & $21^{a}$ & 3.777 & 0.516 & 0.014 & 9.231 \\
\hline & & negative & & 89 & & & & & $(0.009)$ & $(0.005)$ & $(0.739)$ \\
\hline
\end{tabular}

aSignificant difference between the empirical network and the random network $(P<0.001$, Z-test).

${ }^{b}$ Random networks were generated by rewiring all of the links with the same numbers of nodes and edges to the corresponding empirical network. The numbers in parentheses indicate the standard deviation (SD) of topological properties of 1000 random networks.

\section{Figures}



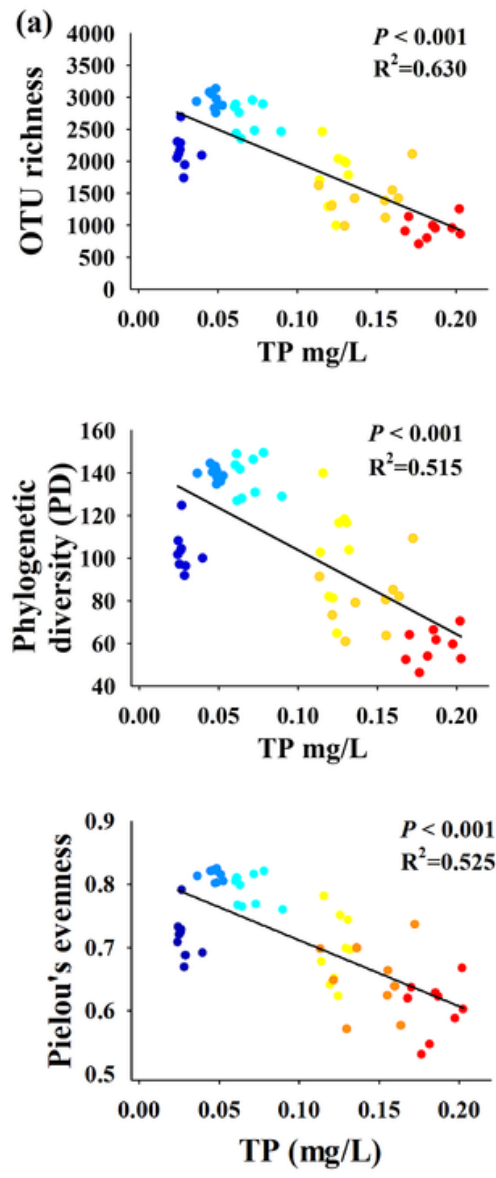
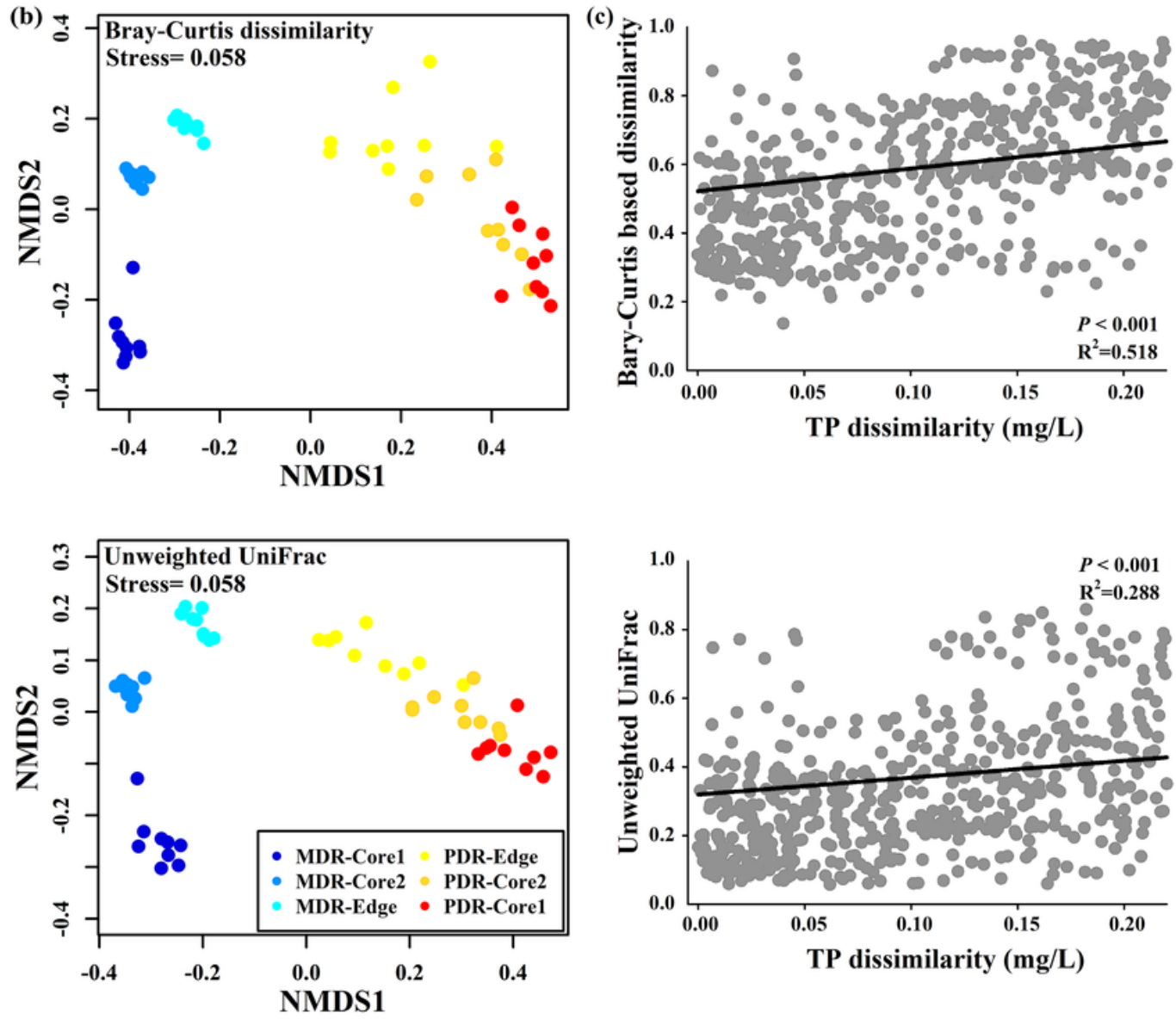

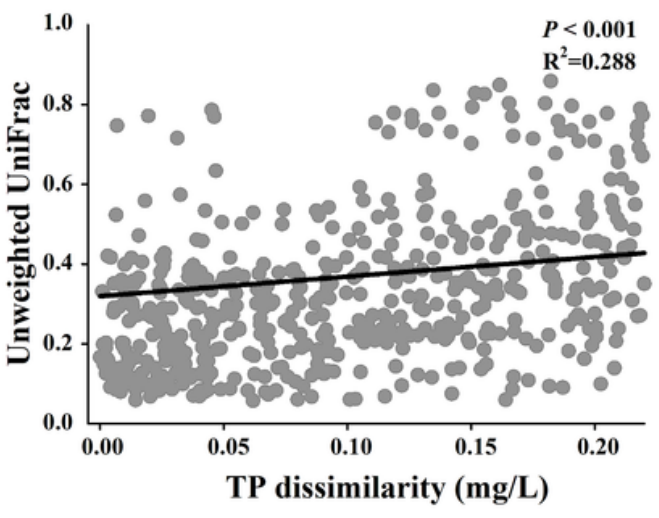

Figure 1

(a) Spearman correlations between operational taxonomic units (OTUs) richness/ Phylogenetic diversity of the bacterioplankton community/ Pielou's evenness index of the bacterioplankton community and total phosphorus (TP) along the regime shift from macrophyte-dominated regime (MDR) and phytoplankton-dominated regime (PDR) in Taihu Lake. (b) Nonmetric multidimensional scaling plots based on taxonomic dissimilarity on the basis of Bray-Curtis distance and phylogenetic dissimilarity on the basis of UniFrac (c) Spearman correlations between taxonomic dissimilarity/phylogenetic dissimilarity and TP in the MDR and PDR in Taihu Lake 
(a)

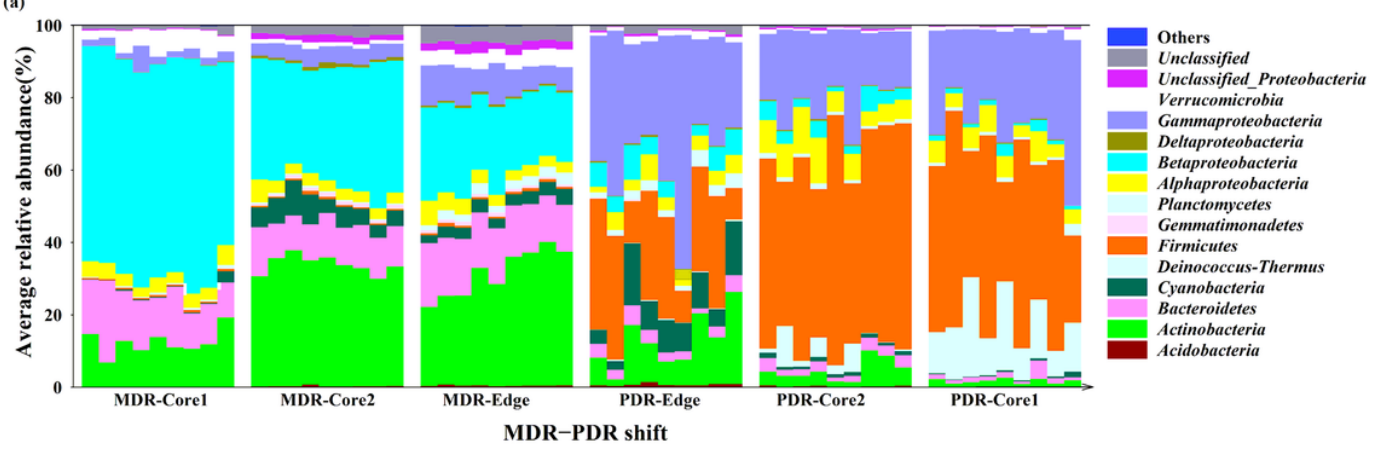

(b)
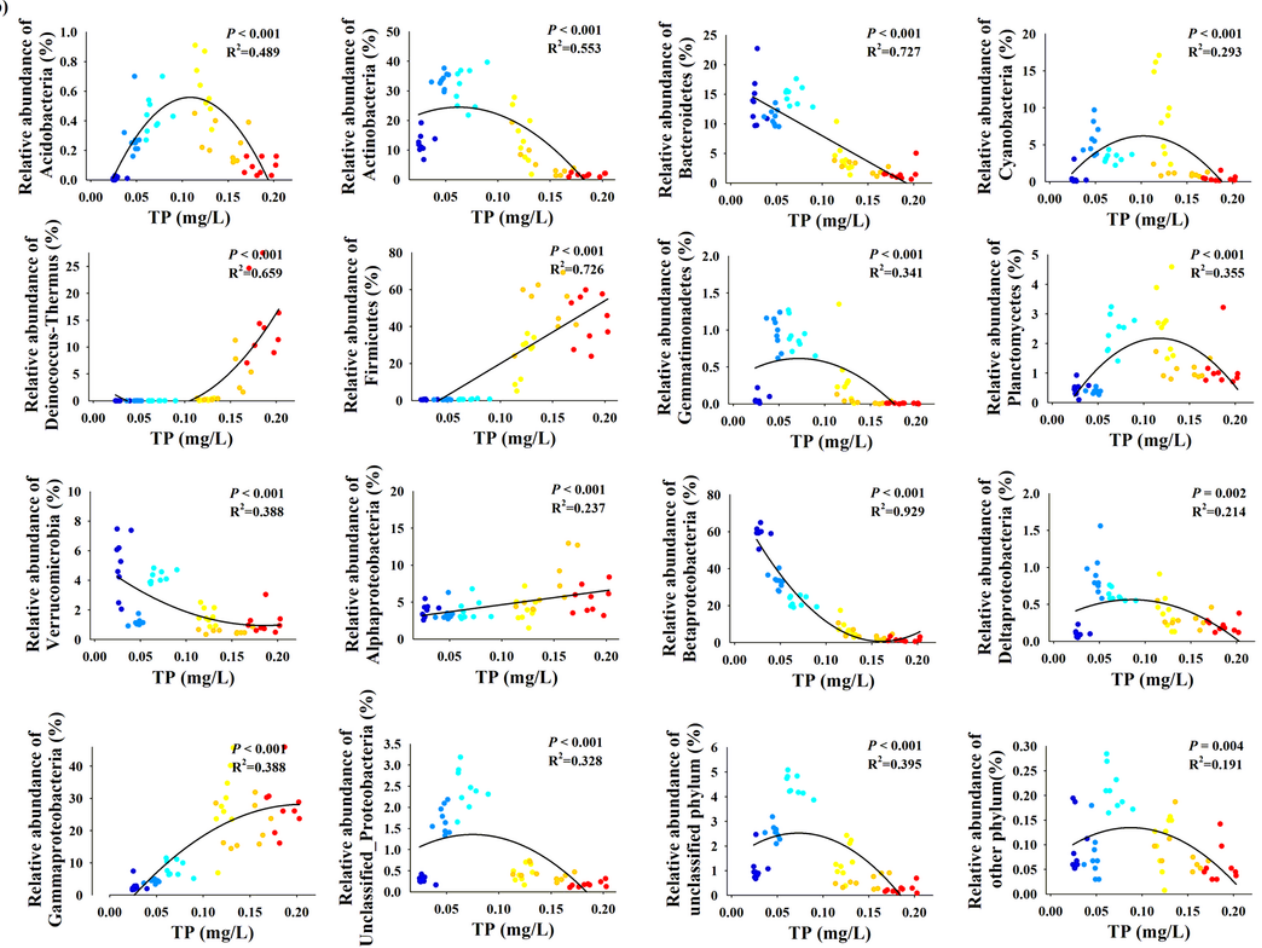

\section{Figure 2}

(a) Relative abundances of bacterial phyla in samples along the regime shift from macrophyte-dominated regime (MDR) and phytoplanktondominated regime (PDR) in Taihu Lake for all the samples. (b) Spearman correlations between the relative abundances of bacterial phyla and total phosphorus (TP), Akaike information criterion values were calculated to select the proper models (Table S1) 


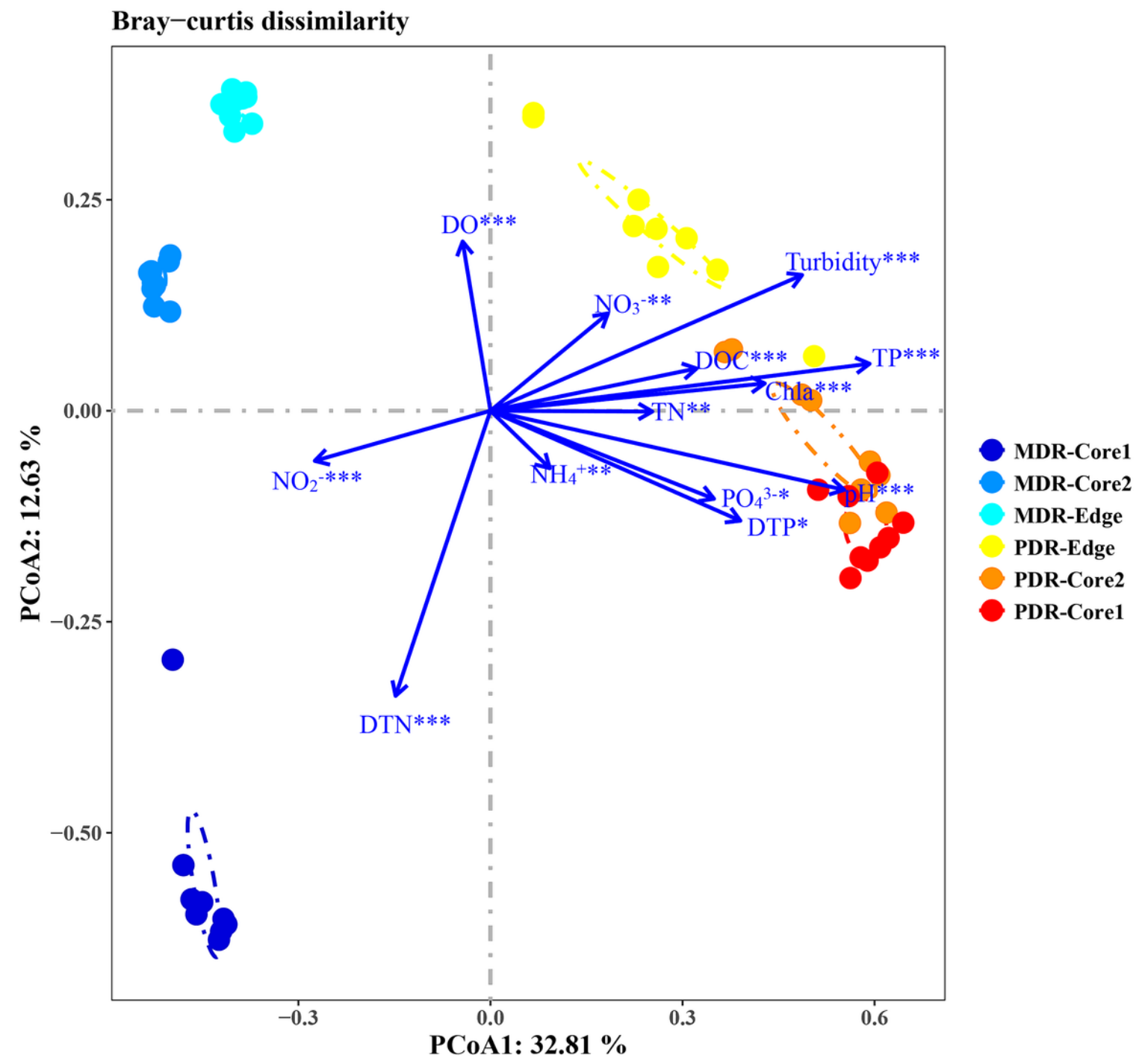

Figure 3

Bray-Curtis dissimilarity based PCoA plot based on all OTUs from six sampling sites across regime shift from macrophyte-dominated regime (MDR) to phytoplankton-dominated regime (PDR) in Taihu Lake. Abbreviations: TN, total nitrogen; DTN, dissolved total nitrogen; NH4+, ammonium nitrogen; NO3-, nitrate nitrogen; NO2-, nitrite nitrogen; TP, total phosphorus; DTP, dissolved total phosphorus; PO43-, phosphate; DOC, dissolved organic carbon; DO, dissolved oxygen; Chl a, chlorophyll a 

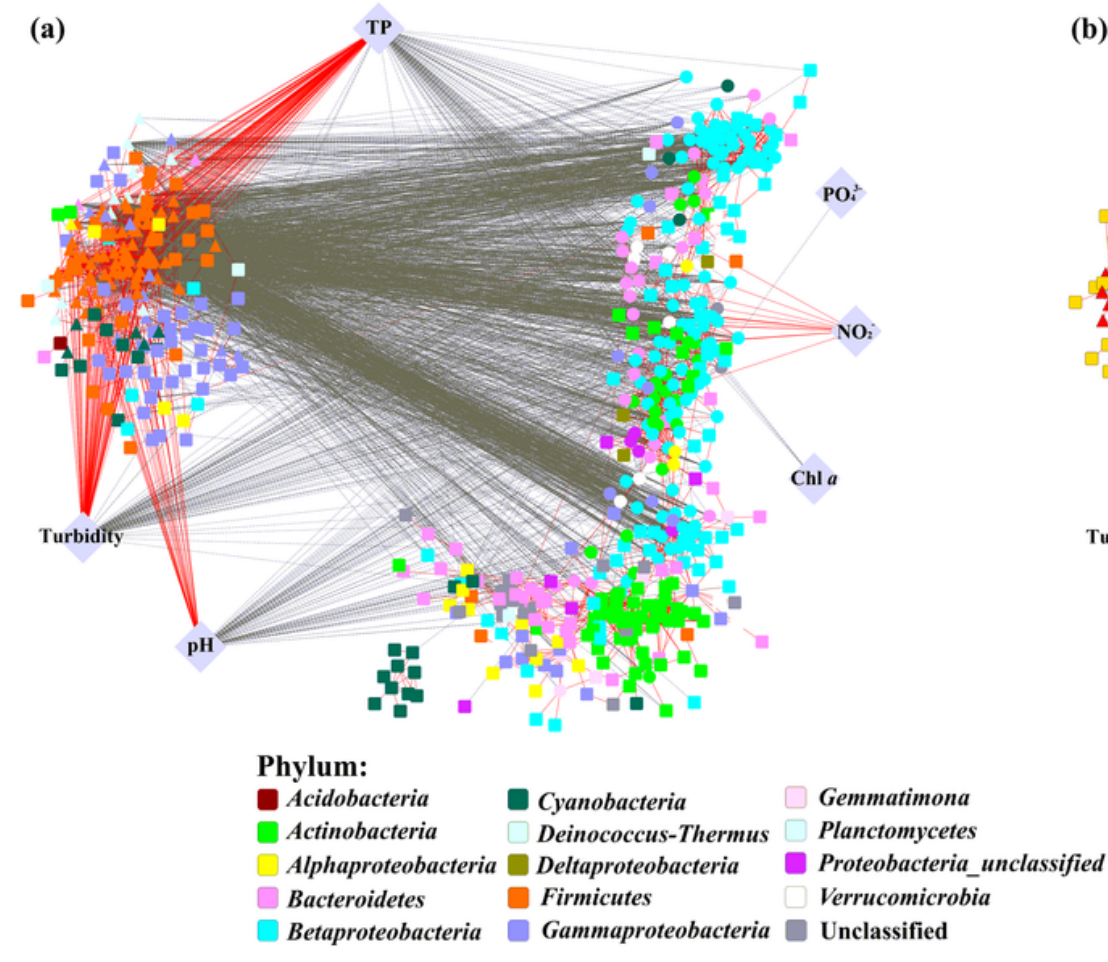

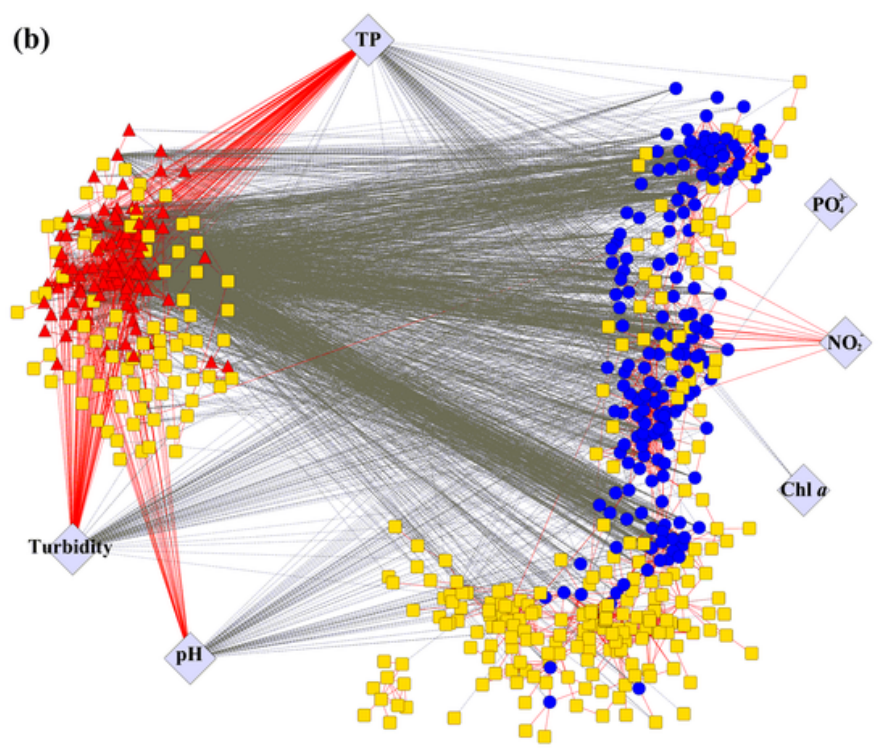

Cluster: Correlations:

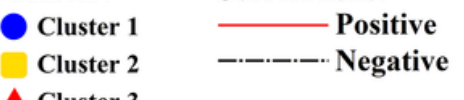

Cluster 3

Figure 4

CoNet-based network of all samples along the regime shift from the macrophyte-dominated regime (MDR) and phytoplankton-dominated (PDR) regime in Taihu Lake clustered with manta. The red solid lines indicate positive correlations and the black lines indicate negative correlations. Different phyla and environmental factors are represented with different colors (a). Cluster identity is further represented by different node shape and colors (b)

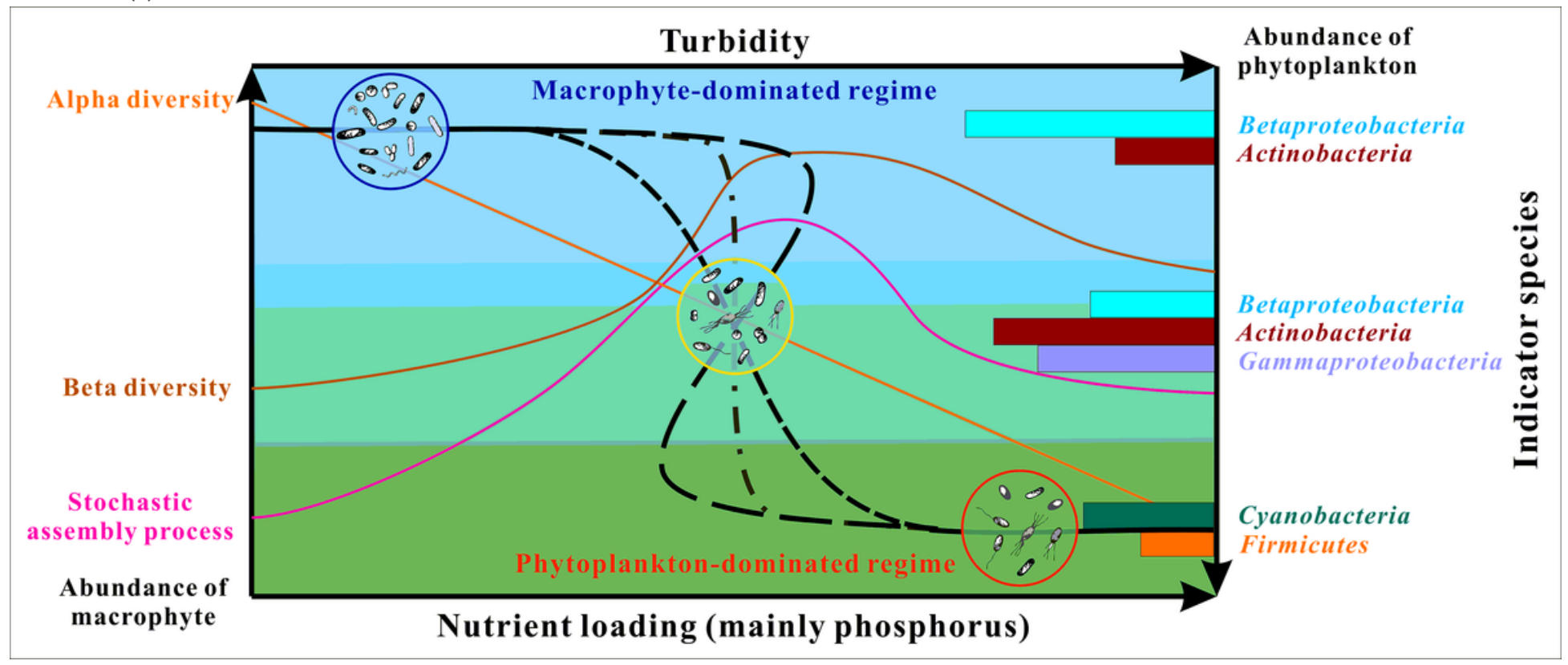

\section{Figure 5}

Conceptual model of the shift in the bacterioplankton community composition along the regime shift from macrophyte-dominated regime (MDR) to phytoplankton-dominated regime (PDR) in a freshwater shallow lake. The unconfirmed dynamic process of regime transition is indicated by thick black dotted line. The change in alpha and beta diversity of bacterioplankton community are indicated by the orange and brown line, respectively. The relative contribution of stochastic assembly processes of bacterioplankton community is indicated by the pink line. The arrows in $x$-axis and $y$-axis indicate the increasing of the environmental attributes (bottom x-axis: nutrient loading, left y-axis: abundance of macrophyte, top $x$-axis: turbidity, right $y$-axis: abundance of phytoplankton). The histogram attached in right $y$-axis indicates the indicator species along regime transition 


\section{Supplementary Files}

This is a list of supplementary files associated with this preprint. Click to download.

- SupplementaryMaterial.docx 